\title{
Lezghian Language
}

National Cancer Institute

\section{Source}

National Cancer Institute. Lezghian Language. NCI Thesaurus. Code C153999.

A Northeast Caucasian language that is spoken mainly by the Lezgin people of Russia. 